INDEPENDENT JOURNAL OF MANAGEMENT \& PRODUCTION (IJM\&P)

http://www.ijmp.jor.br

v. 7, n. 2, April - June 2016

ISSN: 2236-269X

DOI: 10.14807/ijmp.v7i2.415

\title{
MACD - ANALYSIS OF WEAKNESSES OF THE MOST POWERFUL TECHNICAL ANALYSIS TOOL
}

Sanel Halilbegovic International Burch University, Bosnia and Herzegovina E-mail: sanel.halilbegovic@ibu.edu.ba

Submission: 09/12/2015 ABSTRACT

Accept: 19/12/2015

Due to the huge popularization of the stock trading amongst youth, in the recent years more and more of trading and brokerage houses are trying to find a one 'easy to understand' tool for the novice traders. Moving average convergence divergence seems to be the main pick and unfortunately inexperienced traders are relying on this one tool for analysis and trading of various securities. In this paper, I will investigate the validity of MACD as the 'magic wand' when solely used in investment trading decision making. The main limitation of this study is that it could be used more widely across industries and various sizes of companies, funds, and other trading instruments.

Keywords: Moving average convergence divergence (MACD), Technical Analysis, Signal and Profit relation, Stock Market Trading, Profitability 


\section{INTRODUCTION}

Is it because technical analysis doesn't have good coverage in academia or because most of the traders follow fundamental analysis superstars such as Warren Buffet, but technical analysis is getting very little attention. In recent years, fueled with non-fundamental base commodities trading, technical analysis picks up on popularity.

In certain markets technical analysis can provide much more input than fundamental analysis, and it is usually said that where fundamental stops, technical analysis continues as it is based purely on the relationship between supply and demand and not so much on the financial character of the traded instrument.

\section{LITERATURE REVIEW}

What technicians (popular title of technical analysis masters) claim is that indicating ratios, dividend growth model, Black and Scholes model and other popular financial models mean nothing if there is no supply and demand (STOFT, 2002; EDWARDS; MAGEE, 2007).

One of the many available tools of technical trading is something popularly called MACD or Moving Average Convergence Divergence. MACD is known as the most valuable tool in a technician's toolbox and without it most of technical analyses would be impossible.

MACD was developed by a legendary technician mr Gerard Appel who turned his obsession for so called momentum indicators into a MACD as we know it today (Murphy, 2004). MACD actually consists of two lines that are comprised of three moving averages. First one is called MACD line (usually color blue) and the other one is called 'the signal line', usually red color (APPEL, 1979). MACD line is derived as follows:

MACD line $=12$ day Exponential Price average -26 day Exponential Price average (1) 12day exponential price average, minus, 26day exponential price average,

SIGNAL line = 9day exponential average of MACD line

while the "signal" line is derived as a 9day exponential average of MACD line. This $12 / 26 / 9$ is a standard and at the same time 'original recipe' combination of 
DOI: 10.14807/ijmp.v7i2.415

periods, some technicians decide to modify this original combination and make their own, customized combinations.

The 12/26/9 setting got set during 1970s when the standard work week was 6 days, so in effect 12 represents 2 weeks, 26 represents a full month and 9 represents week and a half therefore covering the entire months length. With the arrival of the new customizable and interactive tools, one can easily change the original 12/26/9 structure into something that is a better 'fit' for the investment instrument being analyzed (SHANNON, 2008).

Since the formula is dealing with the 12,26 , and 9 day exponential average it is important to say that exponential moving average is a type of weighted average or an average where some periods, or in this case days, carry more 'weight' than others. For example when a 9 day exponential moving average is calculated, the most recent day is carrying most weight while the day before the most recent day is carrying little bit less weight and so on, to the 9th day that is carrying the least weight therefore placing more importance on the most recent days. (PRADIPBHAI, 2013; NISON, 2001). Exponential average is calculated as:

$$
E P(t)=\alpha * P(t-1)+(1-\alpha)^{*} E P(t-1)
$$

where $\alpha$ is a coefficient of the division of the weight, $P(t-1)$ is the price of the stock at the trading close of the previous day, and $\operatorname{EP}(\mathrm{t}-1)$ is an exponential average calculated for the previous day. Two of the MACD lines cross over each other and the important events are when two lines cross above or below the central or so called 'zero' line.

MACD became highly valued among traders because it becomes extremely powerful especially when for example a strong buy signal is coupled with an increase in the trading volume (DHARAMVEER, 2014; PRING, 1995). On the following chart we see a number of crossovers between MACD and signal lines and each of those crossovers can give a buy signal.

The signal strength (in this research I measure it from 1 to 10 , from weakest to strongest, respectively) depends on the position where the crossover happens. Deeper below the zero line the crossover happens, the stronger the buy signal it is. 
DOI: 10.14807/ijmp.v7i2.415

So, if the crossover happens on or around the zero line, the signal strength is 1 and if the crossover happens on or around the -6 line the signal strength is 10 . For example the first circled crossover happened at the level ' -3 ' so the signal strength would be a ' 6 ', while the second circled crossover happened at the level ' -1 ' so the signal strength would be a ' 2 '.
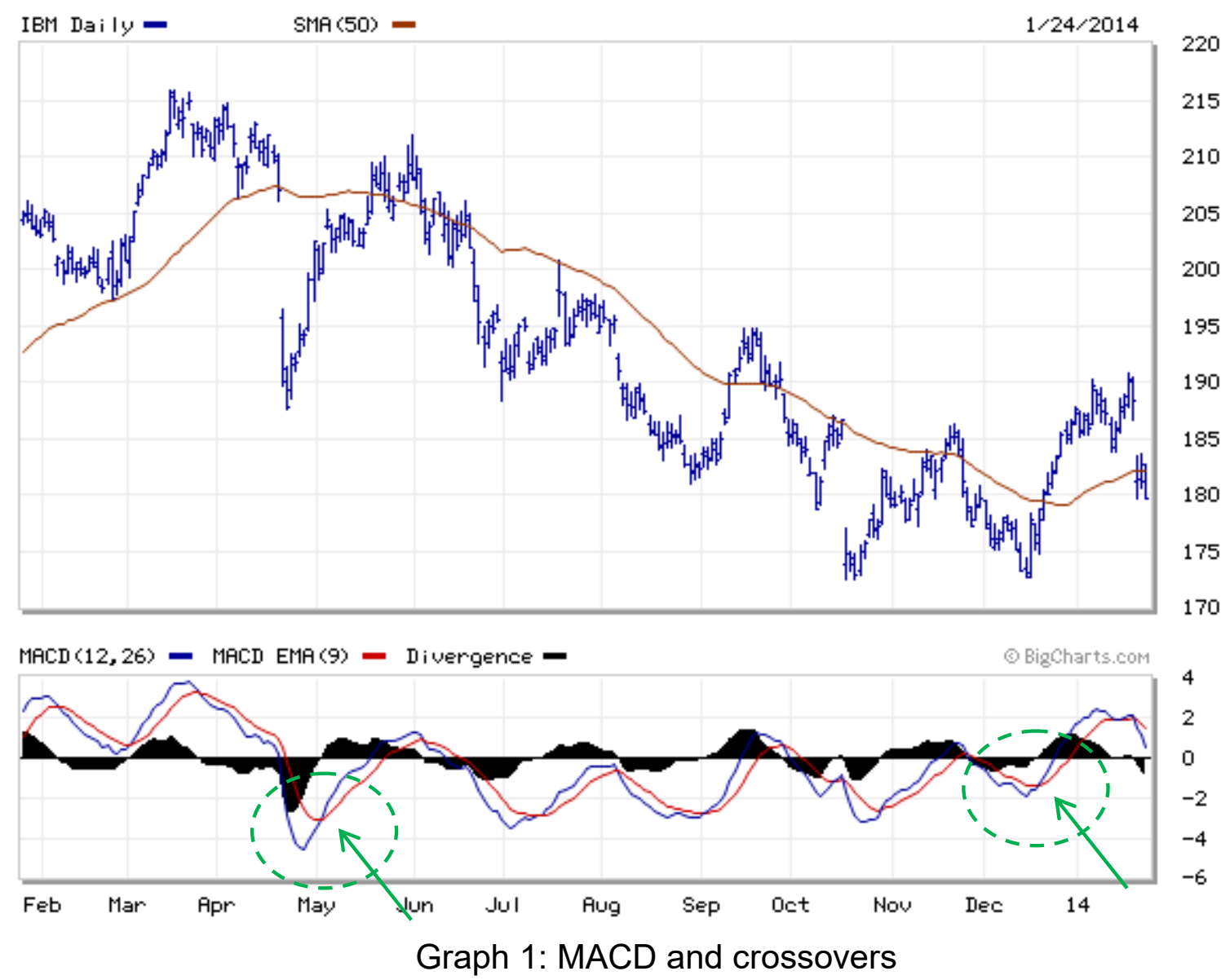

\section{HYPOTHESIS}

The research title alone dictates the logical hypothesis. Key point is to prove or disprove that by using the MACD it is possible to generate investment profit. From this the main hypothesis is derived:

"...With MACD usage as a stock investment indicator, it is not possible to generate a consistent, considerable and sustainable profit..."

This basically means that if the relation between generated profit yield and a signal strength derived by MACD, is not in direct proportion, it means that MACD when used as a standalone investment decision maker does not produce consistent or sizeable profit. 
DOI: $10.14807 /$ ijmp.v7i2.415

The validity of the hypothesis will be determined by the correlation coefficient (' $r$ ') or Pearson's ' $r$ ', as well as ' $r 2$ ' which is the coefficient of determination. If it proofs that the above-mentioned coefficients are rather high or much closer to 1 than to 0 , then we can conclude that the hypothesis 'stands', while if opposite happens, the hypothesis 'falls'.

\section{METHODOLOGY}

The research methods used in this research basically include tracking of the trading history of the chosen firms in the timeframe from September 2008 to September 2013, as well as uncovering the relationship between the signal strength of MACD and the profitability in case the investor reacts on the given signal. This research will dissect collected 5year data about the three companies and try to prove or disprove the hypothesis.

The percent profit yield will be calculated based on the signal of the MACD and the yield will be compared to the strength of the signal given by MACD, so in effect the analysis will portray yield as a dependable variable while MACD signal strength will be depicted as an undependable variable and in the end the connection between those variables will be analyzed by statistical regression.

\subsection{Data Analysis and Discussion}

As mentioned before for each generated MACD signal, a strength level will be assigned from 1-10 (weakest - strongest). On the graph 2, shown below we have the depiction of the price movements of Amazon Inc., and below the price movements, MACD indicator is plotted out. In the given period of 5 years (from 2008-2013), Amazon's MACD generated a total of 17 signals that are shown on the graph 2. The price movement generally has a positive slope with the tendency to continue rising.

There have been some periods of retraction especially in September/October 2011 and after that MACD confirmed a good opportunity to go long with its strong buy signal.

Signal strengths are of a solid distribution ranging from 2-10. 


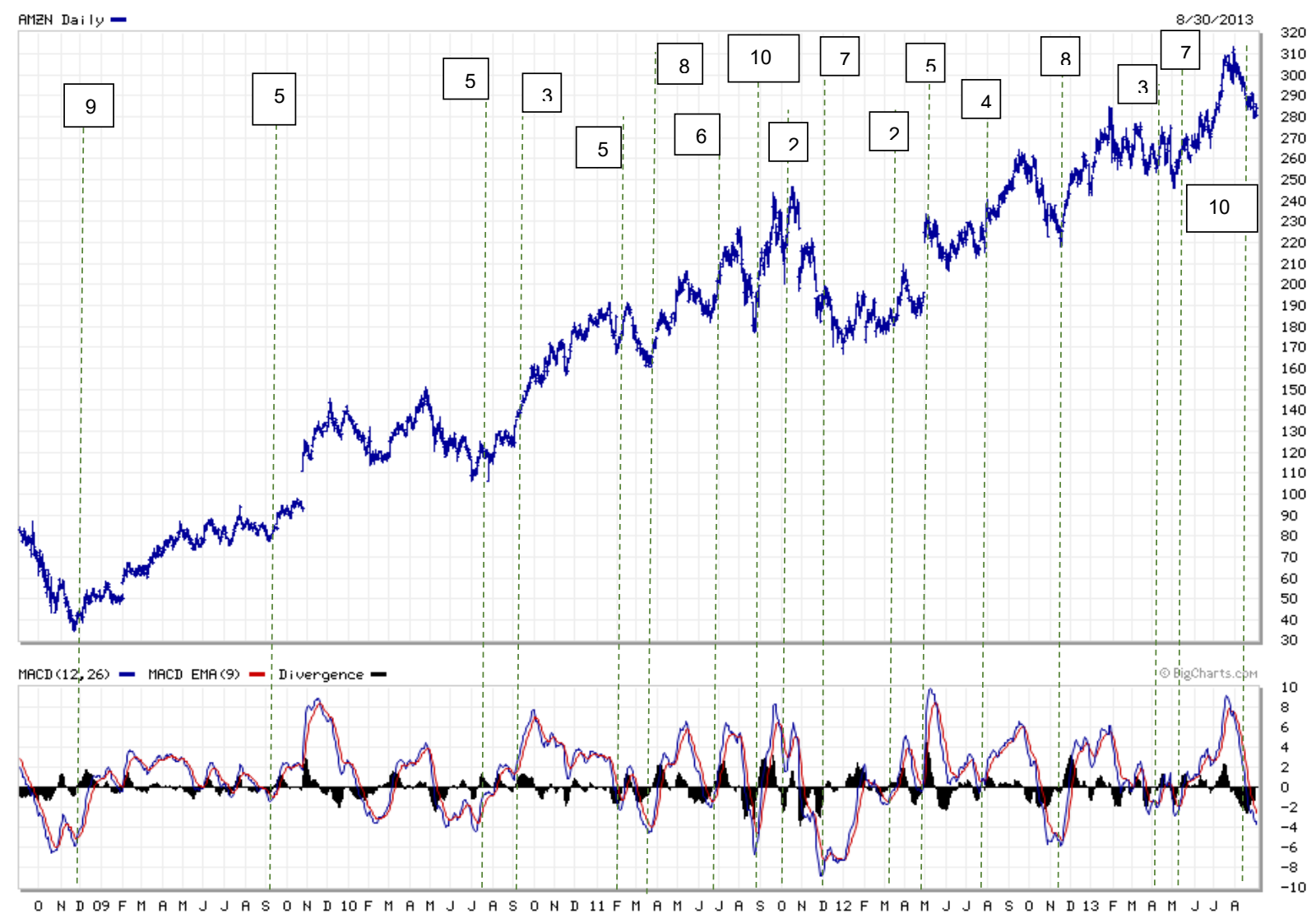

Graph 2: Amazon Inc daily trading over 5 years including MACD

On the graph 3 , shown below we have the depiction of the price movements of Apple Corp, and below the price movements, MACD indicator is plotted out. In the given period of 5 years (from 2008-2013), Apple's MACD generated a total of 19 signals that are shown on the graph 3.

The price movement generally has a positive slope with the tendency to correct itself downwards. What is very interesting is the fact that Apple has touchtested a psychological ceiling at $\$ 100$ and as soon as it touched it the sell-off began.

Signal strengths are of a solid distribution ranging from 2-10. 


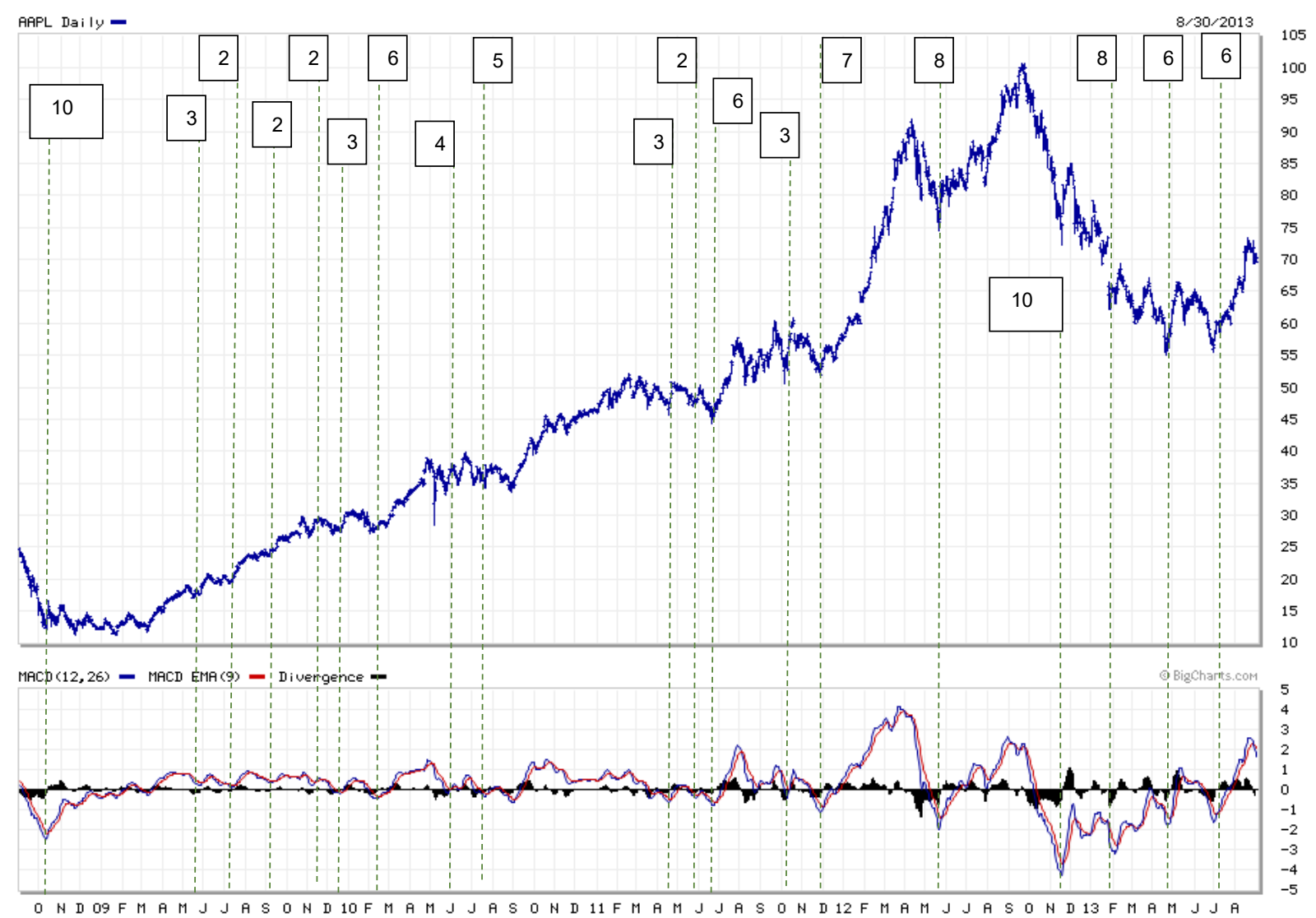

Graph 3: Apple Corp daily trading over 5 years with MACD

On the graph 4, shown below we have the depiction of the price movements of IBM Corporation, and below the price movements, MACD indicator is plotted out. In the given period of 5 years (from 2008-2013), IBM's MACD generated a total of 16 signals that are shown on the graph 4 .

The price movement generally has a positive slope with the tendency to generally continue rising. There is a very good chance that the price will hit a very hard and psychological ceiling at $\$ 200$ per share as this resistance has been tested at least 5 times in the past 6 months.

If the price penetrates the given ceiling and since it was tested on so many occasions, if the price goes north of $\$ 200$, than $\$ 200$ level will become a super strong floor which would represent a good opportunity for a long term investment.

Signal strengths are of a solid distribution ranging from 3-10. 


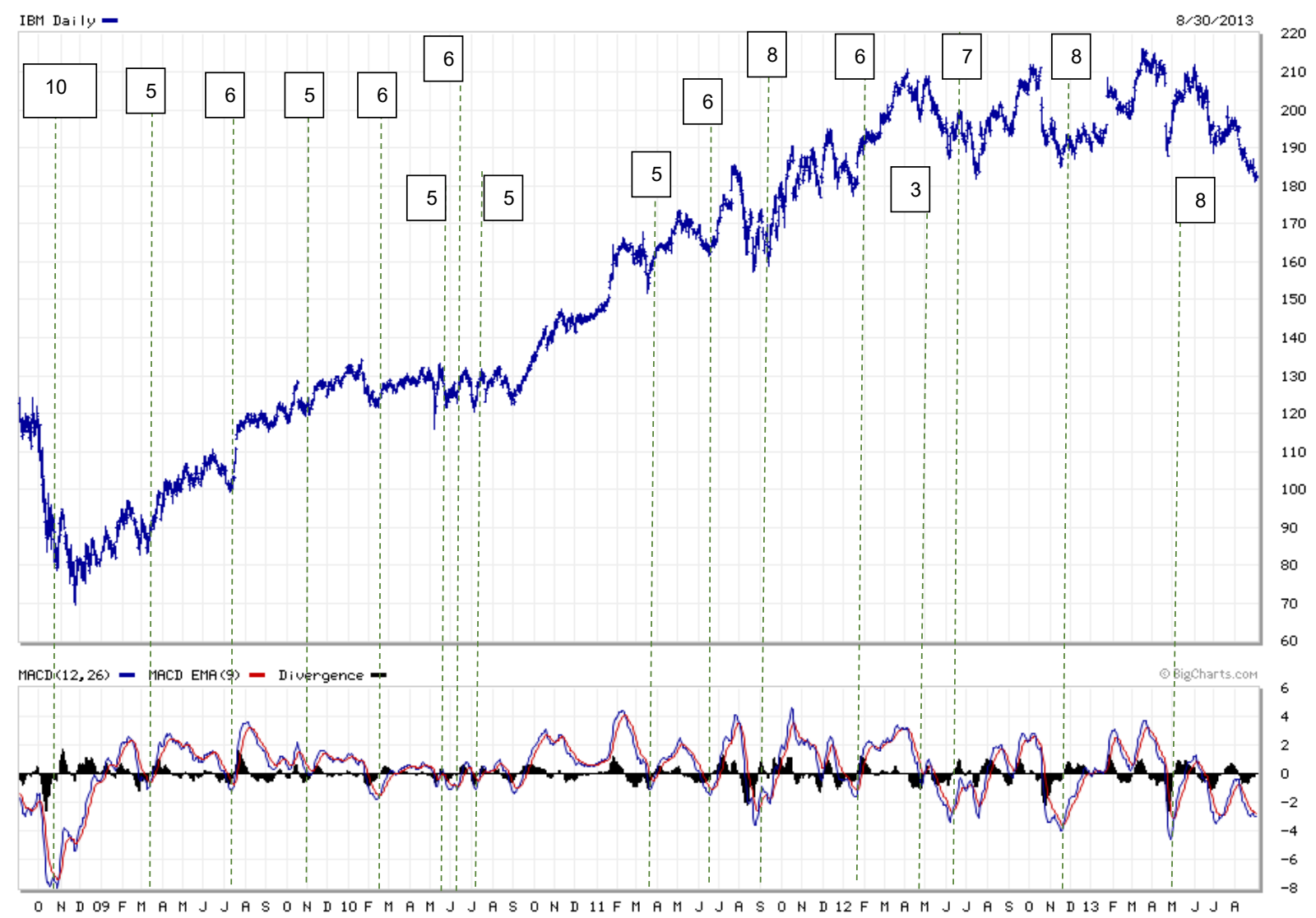

Graph 4: IBM daily trading over 5 years including MACD

A tabular representation of MACD signals for all three companies, their strengths and corresponding profit margins are shown in the table 1 . This table shows all the details such as the date of the signal, price when signal was generated, the actual signal strength and the profit margin that corresponds to the given signal. 


\section{INDEPENDENT JOURNAL OF MANAGEMENT \& PRODUCTION (IJM\&P)}

http://www.ijmp.jor.br

v. 7, n. 2, April - June 2016

ISSN: 2236-269X

DOI: 10.14807/ijmp.v7i2.415

Table 1: tabular depiction of signal strengths and trades for Amazon, Apple and IBM

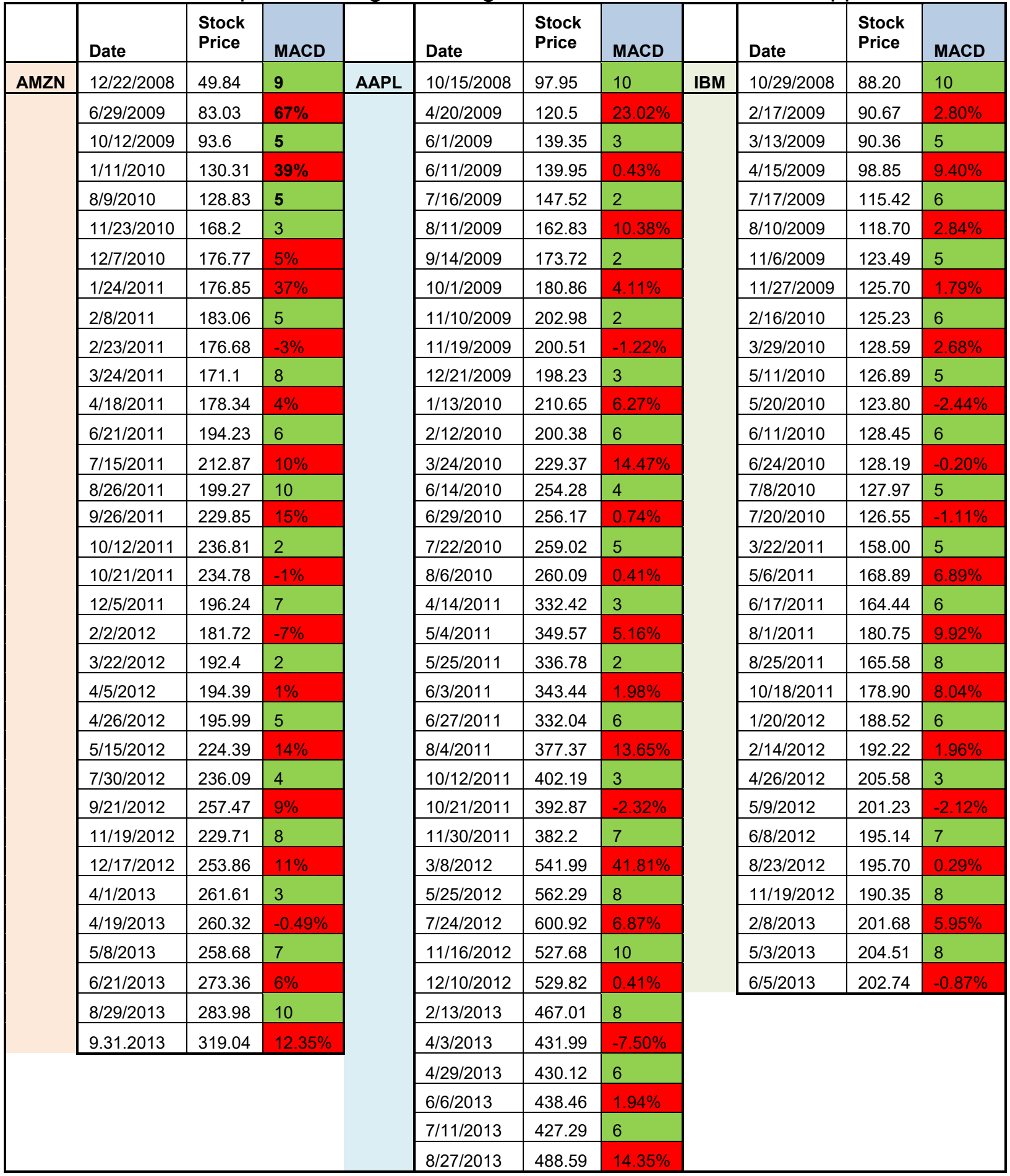

A truncated table showing only the signal strength and the corresponding profit margin is shown in the table 2. 
INDEPENDENT JOURNAL OF MANAGEMENT \& PRODUCTION (IJM\&P)

http://www.ijmp.jor.br

v. 7, n. 2, April - June 2016

ISSN: 2236-269X

DOI: 10.14807/ijmp.v7i2.415

Table 2: Truncated table showing signal strength and corresponding profit margins

\begin{tabular}{|l|l|l|l|l|l|}
\hline \multicolumn{7}{|c|}{ AMZN } & \multicolumn{5}{l}{ IBM } \\
\hline Signal & Profit & Signal & Profit & Signal & Profit \\
\hline 9 & 67.00 & 10 & 23.02 & 10 & 2.80 \\
\hline 5 & 39.00 & 3 & 0.43 & 5 & 9.40 \\
\hline 5 & 37.00 & 2 & 10.38 & 6 & 2.84 \\
\hline 3 & 5.00 & 2 & 4.11 & 5 & 1.79 \\
\hline 5 & -3.00 & 2 & -1.22 & 6 & 2.68 \\
\hline 8 & 4.00 & 3 & 6.27 & 5 & -2.44 \\
\hline 6 & 10.00 & 6 & 14.47 & 6 & -0.20 \\
\hline 10 & 15.00 & 4 & 0.74 & 5 & -1.11 \\
\hline 2 & -1.00 & 5 & 0.41 & 5 & 6.89 \\
\hline 7 & -7.00 & 3 & 5.16 & 6 & 9.92 \\
\hline 2 & 1.00 & 2 & 1.98 & 8 & 8.04 \\
\hline 5 & 14.00 & 6 & 13.65 & 6 & 1.96 \\
\hline 4 & 9.00 & 3 & -2.32 & 3 & -2.12 \\
\hline 8 & 11.00 & 7 & 41.81 & 7 & 0.29 \\
\hline 3 & -0.50 & 8 & 6.87 & 8 & 5.95 \\
\hline 7 & 6.00 & 10 & 0.41 & 8 & -0.87 \\
\hline 10 & 12.35 & 8 & -7.50 & & \\
\hline & & 6 & 1.94 & & \\
\cline { 1 - 4 } & & 6 & 14.35 & & \\
\hline & & & & & \\
\hline
\end{tabular}

\subsection{Findings}

Using the above tables, usable dataset is created and it can be used for the statistical tests that will numerically prove or disprove the hypothesis.

Table 3: Paired Sample Test

\begin{tabular}{|c|c|c|c|c|c|c|c|c|c|}
\hline & \multicolumn{5}{|c|}{ Paired Differences } & \multirow[b]{3}{*}{$\mathrm{t}$} & \multirow[b]{3}{*}{ df } & \multirow{3}{*}{$\begin{array}{l}\text { Sig. } \\
(2- \\
\text { tailed })\end{array}$} \\
\hline & & \multirow[b]{2}{*}{ Mean } & \multirow{2}{*}{$\begin{array}{l}\text { Std. } \\
\text { Deviat } \\
\text { ion }\end{array}$} & \multirow{2}{*}{$\begin{array}{l}\text { Std. } \\
\text { Error } \\
\text { Mean }\end{array}$} & \multicolumn{2}{|c|}{\begin{tabular}{llr}
$95 \%$ & \multicolumn{2}{c}{ Confidence } \\
Interval of & the \\
Difference &
\end{tabular}} & & & \\
\hline & & & & & Lower & Upper & & & \\
\hline & $\begin{array}{l}\text { AMZprofit } \\
\text { APLprofit }\end{array}$ & -.3058 & $\begin{array}{l}20.72 \\
3\end{array}$ & $\begin{array}{l}5.9824 \\
5\end{array}$ & -13.47312 & $\begin{array}{l}12.8614 \\
5\end{array}$ & -.051 & 11 & .960 \\
\hline Pair 2 & $\begin{array}{l}\text { AMZprofit } \\
\text { IBMprofit }\end{array}$ & 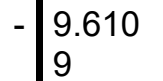 & $\begin{array}{l}13.08 \\
5\end{array}$ & $\begin{array}{l}3.9452 \\
8\end{array}$ & .82027 & $\begin{array}{l}18.4015 \\
5\end{array}$ & 2.436 & 10 & .035 \\
\hline Pair 3 & $\begin{array}{l}\text { APLprofit } \\
\text { IBMprofit }\end{array}$ & \begin{tabular}{l|l}
- & 6.159 \\
0
\end{tabular} & $\begin{array}{l}15.06 \\
4\end{array}$ & $\begin{array}{l}4.5420 \\
1\end{array}$ & -3.96114 & $\begin{array}{l}16.2793 \\
3\end{array}$ & 1.356 & 10 & .205 \\
\hline
\end{tabular}

The profit yields and signal strength of three chosen companies, Amazon, Apple and IBM, were analyzed using paired sample t test.

The paired t-test is used when each observation in one group is paired with a related observation in the other group. In this case profit yields in relation to signal 
DOI: 10.14807/ijmp.v7i2.415

strength of one company are paired to that of another company, e.g. Amazon profit yields are paired with profit yields of Apple and IBM.

Table above demonstrates the results of paired sample $t$ test for three chosen companies. The p-value (level of significance) for pair 2 Amazon Profit-IBM Profit is 0,035 what is lower than 0,05 , so the null hypothesis will be rejected. There exists significant difference in profit yields in relation to signal strength, between Amazon and IBM.

According to the table results, the remaining two pairs, pair 1 and 3 , the difference between companies (Amazon-Apple and Apple-IBM), is not statistically different form zero.

Besides using Paired Sample Test, the regression tool is also used in order to explain the strength of the relationship between independent variable (signal strength) and dependent variable (profit margin).

The relationship between the two variables will be mainly explained by a coefficient of determination or r2. R2 is a statistical measure of how close the data are to the fitted regression line. Coefficient of Determination is calculated as Explained variation / Total variation

$\mathrm{R} 2$ is a number that is always between 0 and $100 \%$ :

- $0 \%$ indicates that the model explains none of the variability of the response data around its mean.

- $100 \%$ indicates that the model explains all the variability of the response data around its mean.

Table 4: Correlations

\begin{tabular}{|ll|l|l|}
\hline & & Profit & Signal \\
\hline Pearson Correlation & Profit & 1.000 & .168 \\
& Signal & .168 & 1.000 \\
\hline Sig. (1-tailed) & Profit &. & .117 \\
& Signal & .117 &. \\
\hline $\mathrm{N}$ & Profit & 52 & 52 \\
& Signal & 52 & 52 \\
\hline
\end{tabular}


INDEPENDENT JOURNAL OF MANAGEMENT \& PRODUCTION (IJM\&P)

http://www.ijmp.jor.br

v. 7, n. 2, April - June 2016

ISSN: 2236-269X

DOI: 10.14807/ijmp.v7i2.415

Pearson correlation measures the strength and direction of the linear relationship between the two variables. The Pearson correlation between profit yields and signal strength is 0.168 , which means that there is no strong correlation between profit yields and signal strength in relation to MACD indicator.

Table 5: Model Summary

\begin{tabular}{|c|c|c|c|c|c|c|c|}
\hline \multicolumn{8}{|l|}{ Model Summary } \\
\hline \multirow[t]{2}{*}{ Adjusted R Square } & \multirow{2}{*}{$\begin{array}{l}\text { Std. } \\
\text { Error of } \\
\text { the } \\
\text { Estimate }\end{array}$} & \multicolumn{5}{|l|}{ Change Statistics } & \multirow{2}{*}{$\begin{array}{l}\text { Durbin- } \\
\text { Watson }\end{array}$} \\
\hline & & $\begin{array}{ll}\mathrm{R} & \text { Square } \\
\text { Change } & \end{array}$ & $\begin{array}{l}\mathrm{F} \\
\text { Change }\end{array}$ & $\mathrm{df1}$ & df2 & $\begin{array}{l}\text { Sig. F } \\
\text { Change }\end{array}$ & \\
\hline 0.009 & 10.181 & 0.028 & 1.453 & 1 & 50 & 0.234 & 1.627 \\
\hline
\end{tabular}

$\mathrm{R}^{2}$ describes the proportion of variance in the dependent variable (profit yields) which can be explained by the independent variables (signal strength). It is an overall measure of the strength of association and does not reflect the extent to which any particular independent variable is associated with the dependent variable. In this case, $R^{2}$ is 0.028 , what means that just $2.8 \%$ of variance in profit yields can be described by the signal strength which is related only to the MACD indicator.

\section{Table 6 - Standardized and Unstandardized Coefficients}

\begin{tabular}{|ll|l|l|l|l|l|}
\hline \multicolumn{2}{|l|}{ Model } & \multicolumn{2}{|l|}{\begin{tabular}{l} 
Unstandardized \\
\cline { 3 - 5 }
\end{tabular}} & \multicolumn{1}{|l|}{$\begin{array}{l}\text { Standardized } \\
\text { Coefficients }\end{array}$} & & \\
\cline { 3 - 5 } & $\mathrm{B}$ & Std. Error & Beta & $\mathrm{t}$ & Sig. \\
\hline 1 & (Constant) & 2.348 & 3.654 & & .643 & .523 \\
& Signal & .718 & .596 & .168 & 1.205 & .234 \\
\hline
\end{tabular}

a. Dependent Variable: Profit

B Coefficient - These are the values for the regression equation for predicting the dependent variable from the independent variable. From the table above, we can see that the $B$ coefficient for independent variable - signal strength is 0.718 , what means that for every unit of increase in signal strength, it is predicted that the profit yield will increase for 0.718 . However, the corresponding p-value is 0.234 which is higher than 0.05 , what means that coefficient for signal strength is not significantly different from zero.

\section{CONCLUSION}

Based on the above research and analysis, the conclusion is that the hypothesis "...With MACD usage as a stock investment indicator, it is not possible to generate a consistent, considerable and sustainable profit..." stands, as the 
DOI: 10.14807/ijmp.v7i2.415

statistical tools have shown that the relationship between signal strength and the generated profit is very weak.

This applies mainly to young and upcoming investors who are lured mainly by FOREX brokers who claim that huge profits can be made using 'a simple but proven tool called MACD'. Investments in any kind of financial instruments must be based on multiple indicators and even if all selected indicators 'agree' on the signal, the investor should be cautious and protect themselves via stops, hedging or other lossprevention techniques.

The limitations of this paper come mainly in the form of the lack of width across industries and across the markets as it would be interesting to see does the same thing happen over the World's markets and different industries. These limitations can serve as a 'seed' and as a igniter for the upcoming graduates and master and PhD candidates who could develop and drill-down this topic fatherly.

\section{REFERENCES}

APPEL, G. (1979) The Moving Average Convergence Divergence Method, Great Neck, NY: Signalert

DHARAMVEER, D. (2014) Technical Analysis of Indian Forex Market, GEInternational Journal of Management Research, p. 4-6.

Edwards R.; Magee J. (2007). Technical Analysis of Stock Trends, AMACOM, p. 3654.

MURPHY, J. (2004) Intermarket Analysis - Profiting from Global Markets, Wiley Trading

NISON, S. (2001) Japanese Candlestick Charting Techniques, Prentice Hall, p. 81-108.

PRADIPBHAI, N. (2013) Comparison Between Exponential Moving Average Based MACD with Simple Moving Average MACD of Technical Analysis, International Journal of Scientific Research, p. 6-14.

PRING, M. (1995) Investment Psychology Explained, Wiley, p. 45-63.

SHANNON, B. (2008) Technical Analysis Using Multiple Timeframes, LifeVest Publishing Inc., p. 90-108

STOFT, S. (2002) Power System Economics, Wiley/InterScience, p. 54-63.

SOURCE OF GRAPHS: http://bigcharts.marketwatch.com 